\title{
Lsp family proteins regulate antibiotic biosynthesis in Lysobacter enzymogenes $\mathrm{OH} 11$
}

\author{
Ruping Wang ${ }^{1,2}$, Huiyong Xu1', Yangyang Zhao', Juan Zhang², Gary Y Yuen ${ }^{3}$, Guoliang Qian² \\ and Fengquan $\mathrm{Liu}^{1,2^{*}}$
}

\begin{abstract}
Ax21 family proteins have been shown to play regulatory roles in plant- and animal-pathogenic species in the bacterial family Xanthomonadaceae, but the protein have not been investigated previously in the non-pathogenic members of this bacterial family. Lysobacter enzymogenes, is a non-pathogenic species known for its capacity as a biocontrol agent of plant pathogens. It is also noted for the production of antimicrobial secondary metabolites, heat stable antifungal factor (HSAF) and WAP-8294A2, that have potential for agricultural and pharmaceutical applications. The species also displays type IV pili-dependent twitching motility and the production of multiple extracellular lytic enzymes as additional biocontrol-related traits. Here, we show that L. enzymogenes strain $\mathrm{OH} 11$ possesses three genes widely separated in the $\mathrm{OH} 11$ genome that code for unique Ax21-like proteins (Lsp). By comparing the wildtype $\mathrm{OH} 11$ with mutant strains having a single Isp gene or a combination of Isp genes deleted, we found that each Lsp protein individually is involved in positive regulation of HSAF and WAP-8294A2 biosynthesis, but the proteins collectively do not exert additive effects in this regulation. None of the Lsp proteins were found to influence twitching motility or the production of three extracellular lytic enzymes. This study is the first to provide evidence linking Ax21-family proteins to antibiotic biosynthesis and, hence, adds new insights into the diversity of regulatory functions of Ax 21 family proteins in bacteria.
\end{abstract}

Keywords: Lysobacter, Antibiotic, Lsp, HSAF, WAP-8294A2, Regulation

\section{Introduction}

The Ax21 protein family consists of proteins related to Ax21, which was originally identified in the rice-pathogenic bacterium, Xanthomonas oryzae pv. oryzae (Xoo) and thought to activate XA21-mediated immunity in rice (Lee et al. 2009). This protein (referred to as $A x 21_{\text {Xoo }}$ in the present study), however, was recently shown not to be involved in triggering an immune response in rice carrying the XA21 pattern recognition receptor (Bahar et al. 2014). This role was found to be performed, instead, by $\operatorname{RaxX}$ (Pruitt et al. 2015). In addition, Ax21 Xoo was described originally as being secreted by a type I-secretion system (Lee et al. 2009), but it was shown later to be an outer membrane protein whose secretion is associated

\footnotetext{
${ }^{*}$ Correspondence: fqliu20011@sina.com

1 Institute of Plant Protection, Jiangsu Academy of Agricultural Sciences, Nanjing 210014, China

Full list of author information is available at the end of the article
}

with outer membrane vesicles (Bahar et al. 2014), and therefore Ax21 Xoo was renamed Omp1X (outer membrane protein 1 in Xoo) (Park et al. 2014). Although the role of $\mathrm{Ax} 21_{\mathrm{Xoo}}$ in the pathogenicity of Xoo is still unclear, it does function in Xoo in regulating cell motility, biofilm formation, and expression of signal transduction proteins (Park et al. 2014). Furthermore, we recently demonstrated that $\mathrm{Ax} 21_{\mathrm{Xoc}}$, which is the homologous protein in $X$. oryzae pv. oryzicola (Xoc), the causal agent of bacterial streak disease on rice, is indispensable for full virulence and biofilm formation by Xoc (Qian et al. 2013). Ax21-family proteins also have been studied in Stenotrophomonas maltophilia, a human pathogenic species related to Xoo and Xoc. Two Ax21-homologous proteins (Smlt0378 and Smlt0184) were found to be produced by S. maltophilia and their secretion via outer membrane vesicles was confirmed (Devos et al. 2015). One protein, Smlt0378, was shown to act as a cell-cell signal that plays a crucial regulatory role in cell motility and virulence 
in S. maltophilia (Ferrer-Navarro et al. 2013; McCarthy et al. 2011).

All previous studies on the function of Ax21 family proteins were limited to plant or human pathogenic species in the bacterial family Xanthomonadaceae. The existence and functionality of Ax21 family proteins in non-pathogenic bacteria has not been reported. The genus Lysobacter is a member of the Xanthomonadaceae that contains non-pathogenic species that have been isolated from various ecological habitats (Christensen and Cook 1978; Hayward et al. 2010). The importance of Lysobacter to the agricultural and pharmaceutical industries has been increasingly recognized because members of the genus are recognized as biological control agents against plant pathogens (Kobayashi and Yuen 2007) and as producers of antibiotics with great potential as new antimicrobial pesticides and drugs (Xie et al. 2012). One antibiotic of particular note is heat stable antifungal factor (HSAF), which is a tetramate-containing macrocyclic lactam with broad-spectrum antifungal activity produced by $L$. enzymogenes (Yu et al. 2007; Li et al. 2008). This antibiotic is unique in its mode of action, disrupting the biosynthesis of membrane sphingolipids, and it also has a distinctive biosynthetic mechanism (Li et al. 2006, 2014; Lou et al. 2011). Another antibiotic produced by L. enzymogenes is WAP-8294A2, a cyclic lipodepsipeptide antibiotic that has activity against Gram-positive bacteria (Kato et al. 1997; Zhang et al. 2011). Because WAP-8294A2 exhibits high anti-MRSA (methicillin-resistant Staphylococcus aureus) activity, it is particularly important in medical therapy (Kato et al. 1997; Zhang et al. 2011). In addition to these secondary metabolites, L. enzymogenes also produces multiple extracellular lytic enzymes that degrade fungal cell walls components and play important roles in the biological control activity of L. enzymogenes (Zhang and Yuen 2000; Palumbo et al. 2003). Furthermore, $L$. enzymogenes produces type IV pili (T4P), which are critical to twitching motility (movement on solid surfaces) and attachment to substrates such as fungal hyphae (Kobayashi et al. 2005; Patel et al. 2011, 2013).

Knowledge of how these traits in L. enzymogenes are regulated individually or collectively could facilitate the application of strains for pharmaceutical and biological control purposes, and recent research has begun shed light on this topic. We previously showed that a small fatty acid $L e$ DSF3 functions as a cell-cell signal to regulate HSAF biosynthesis via the RpfC/RpfG two-component transduction system and a global transcriptional regulator Clp in L. enzymogenes (Qian et al. 2013; Wang et al. 2014; Han et al. 2015). The regulator Clp also controls the production of several extracellular enzymes and twitching motility (Wang et al. 2014). Furthermore, the solo LuxR regulator, LesR, and the response regulator,
PilG, were both identified as key factors in modulating HSAF biosynthesis, while only PilG was also involved in regulating twitching motility (Qian et al. 2014; Zhou et al. 2015).

Despite such progress, however, our understanding of the mechanisms regulating antibiotic, lytic enzyme and T4P production in L. enzymogenes is still incomplete. Given that Ax21 family proteins produced by plant and animal-pathogenic members of the Xanthomonadaceae have been implicated in cell-cell signaling and regulation of cell motility and other virulence-related traits, we conducted this study to determine whether the non-pathogenic bacterium L. enzymogenes produces a Ax 21 family protein, and if so, what roles the protein plays in the regulation of antibiotics and lytic enzyme production and motility. In the present work, we found that L. enzymogenes strain $\mathrm{OH} 11$ possesses three $\mathrm{Ax} 21_{\mathrm{Xoo}}$-like proteins. Because these molecules were small proteins unique to L. enzymogenes, we designated them as Lsp1, Lsp2, and Lsp3. All three were found to regulate the biosynthesis of the antibiotic HSAF and WAP-8294A2, but none were involved in regulating T4P-dependent twitching motility and extracellular lytic enzyme production.

\section{Materials and methods}

\section{Bacterial strains, plasmids and growth conditions}

The bacterial strains and plasmids used in this study are listed in Table 1. Escherichia coli strain DH5 $\alpha$ was used for vector construction and grown in LB broth at $37^{\circ} \mathrm{C}$. Unless otherwise stated, the wild-type $\mathrm{OH} 11$ strain of L. enzymogenes and its derivatives were grown in LB medium at $28{ }^{\circ} \mathrm{C}$. When required, kanamycin $(\mathrm{Km})$ and gentamicin $(\mathrm{Gm})$ were added to final concentrations ranging from 25 to $150 \mu \mathrm{g} / \mathrm{mL}$.

\section{Mutant generation and complementation}

Wild-type OH11 was used as the parent strain for generation of gene in-frame deletion mutants as described previously (Qian et al. 2012). The primers used in this procedure are listed in Table 2. In brief, two pairs of primers were used to amplify an upstream and downstream homologue arm of each lsp gene by polymerase chain reaction (PCR). The two homologue arms corresponding to each $l s p$ gene were cloned into the appropriate sites of the suicide vector pEX18GM, resulting in the final construct (Table 1). This final construct was transformed into wild-type cells by electrotransformation, as described previously (Han et al. 2015). Transformants were selected on LB plates in the presence of $\mathrm{Km}$ $(100 \mu \mathrm{g} / \mathrm{mL})$ and $\mathrm{Gm}(150 \mu \mathrm{g} / \mathrm{mL})$ but without sucrose. The positive colonies were selected and further plated on LB plates supplemented with $10 \%$ (weight/volume) sucrose and $\mathrm{Km}(100 \mu \mathrm{g} / \mathrm{mL})$ to screen for resolution of 
Table 1 Bacterial strains and plasmids used in this study

\begin{tabular}{|c|c|c|}
\hline Strains and plasmids & Characteristics $^{\mathbf{a}}$ & Source or citation \\
\hline \multicolumn{3}{|l|}{ Lysobacter enzymogenes } \\
\hline $\mathrm{OH} 11$ & Wild type, $\mathrm{Km}^{\mathrm{R}}$ & $\begin{array}{l}\text { Qian et al. (2009) } \\
\text { CGMCC No. } 1978\end{array}$ \\
\hline$\Delta / s p 1$ & Ispl in-frame deletion mutant, $\mathrm{Km}^{\mathrm{R}}$ & This study \\
\hline$\Delta / s p 2$ & Isp2 in-frame deletion mutant, $\mathrm{Km}^{\mathrm{R}}$ & This study \\
\hline$\Delta / s p 3$ & Isp3 in-frame deletion mutant, $\mathrm{Km}^{\mathrm{R}}$ & This study \\
\hline$\Delta / s p 1(\mid s p 1)$ & $\Delta / s p 1$ harboring plasmid pBBR-Ispl, $\mathrm{Gm}^{\mathrm{R}}, \mathrm{Km}^{\mathrm{R}}$ & This study \\
\hline$\Delta / s p 2(/ s p 2)$ & $\Delta / s p 2$ harboring plasmid pBBR-Isp2, $\mathrm{Gm}^{\mathrm{R}}, \mathrm{Km}^{\mathrm{R}}$ & This study \\
\hline$\Delta / s p 3(/ s p 3)$ & $\Delta / s p 3$ harboring plasmid pBBR-/sp3, $\mathrm{Gm}^{\mathrm{R}}, \mathrm{Km}^{\mathrm{R}}$ & This study \\
\hline$\Delta / s p l(p B B R)$ & $\Delta / s p 1$ harboring plasmid pBBR1-MCS5, Gm, $\mathrm{Km}^{R}$ & This study \\
\hline$\Delta / s p 2(p B B R)$ & $\Delta / s p 2$ harboring plasmid pBBR1-MCS5, $\mathrm{Gm}^{R}, \mathrm{Km}^{R}$ & This study \\
\hline$\triangle / s p 3(\mathrm{pBBR})$ & $\Delta / s p 3$ harboring plasmid pBBR1-MCS5, Gm ${ }^{R}, \mathrm{Km}^{R}$ & This study \\
\hline$\Delta / s p 12$ & The $/ s p 1 \& / s p 2$ deletion mutant, $\mathrm{Km}^{\mathrm{R}}$ & This study \\
\hline$\Delta / s p 23$ & The Isp2\& Isp3 deletion mutant, $\mathrm{Km}^{\mathrm{R}}$ & This study \\
\hline$\Delta / s p 13$ & The Isp1\& Isp3 deletion mutant, $\mathrm{Km}^{\mathrm{R}}$ & This study \\
\hline$\Delta / s p 123$ & The triple Isp deletion mutant, $\mathrm{Km}^{\mathrm{R}}$ & This study \\
\hline \multicolumn{3}{|l|}{ Escherichia coli } \\
\hline $\mathrm{DH} 5 \mathrm{a}$ & $\begin{array}{l}\left.\mathrm{F}^{-}, \text {} \varphi 80 \mathrm{~d} l a c Z \triangle M 15, \triangle(\text { lacZYA-argF }) \cup 169, \text { deoR, recA1, endA1, hsdR17( } r_{\mathrm{k}}^{-}, \mathrm{m}_{\mathrm{k}}^{+}\right), \text {phoA, supE44, } \lambda^{-} \text {, thi-1, } \\
\text { gyrA96 }\end{array}$ & Qian et al. (2012) \\
\hline \multicolumn{3}{|l|}{ Plasmids } \\
\hline pEX18GM & Suicide vector with a sacB gene, $\mathrm{Gm}^{\mathrm{R}}$ & Hoang et al. (1998) \\
\hline pBBR1-MCS5 & Broad-host-range vector with a $\mathrm{P}_{\text {lac }}$ promoter & Kovach et al. (1995) \\
\hline pEX18-Isp1 & pEX18GM with two flanking fragments of $/ s p 1, \mathrm{Gm}^{\mathrm{R}}$ & This study \\
\hline pEX18-Isp2 & pEX18GM with two flanking fragments of $/ s p 2, \mathrm{Gm}^{R}$ & This study \\
\hline pEX18-/sp3 & pEX18GM with two flanking fragments of $/ s p 3, \mathrm{Gm}^{\mathrm{R}}$ & This study \\
\hline pBBR-Isp1 & pBBR1-MCS5 cloned with a 1275-bp fragment containing intact Isp 1 and its predicted promoter & This study \\
\hline pBBR-Isp2 & pBBR1-MCS5 cloned with a 1591-bp fragment containing intact Isp2 and its predicted promoter & This study \\
\hline pBBR-Isp3 & pBBR1-MCS5 cloned with a 1655-bp fragment containing intact Isp3 and its predicted promoter & This study \\
\hline
\end{tabular}

a $\mathrm{Km}^{\mathrm{R}}, \mathrm{Gm}^{\mathrm{R}}=$ Kanamycin-, Gentamicin-, respectively

the construct by a second cross-over event. The resultant mutants were validated by a PCR approach using the respective primers (Table 2 ). To generate a mutant with two deleted $l s p$ genes (i.e., $\Delta l s p 12, \Delta l s p 23$, or $\Delta l s p 13$ ), the suicide vector $\mathrm{pEX} 18 \mathrm{GM}$ containing one of the lsp genes was introduced into a mutant strain with a different $l s p$ gene already deleted. Similarly, the triple mutant $\Delta l s p 123$ was generated by introduction of pEX18GM-lsp2 into $\Delta l s p 13$. All the single, double and triple mutants generated in this study were verified by PCR (Additional file 1: Tables S1, S2). For complementation, the DNA fragment containing each full-length $l s p$ gene and its native promoter region was amplified from strain OH11 by PCR with the respective primer pairs (Table 2). Each DNA fragment was cloned into the broad-host vector pBBR1MCS5 (Table 1), and which was then introduced into the corresponding $l s p$ mutant, resulting in generation of the plasmid-based complemented strain.

\section{Observation of twitching motility}

Strain OH11 and its derivatives were examined for twitching motility as described previously (Wang et al. 2014; Zhou et al. 2015). In brief, a thin layer of an agar medium (1/20 TSA containing $1.8 \%$ agar) was applied to a sterilized microscope slide and allowed to harden. The edge of a sterilized coverslip was dipped into a cell suspension of the bacterial strain and then gently pressed onto the surface of the agar, creating a thin inoculation line. After $24 \mathrm{~h}$ incubation, the bacterial culture on the microscope slide was observed under a compound microscope at $640 \times$ magnification without a coverslip. Twitching motility was evident in the form of individual bacterial cells or small clusters of cells at the colony margin growing away from the main colony (Wang et al. 2014; Reichenbach 2006). Three replicate slides for each bacterial strain treatment were examined, and the experiment was performed three times. 
Table 2 Primers used for mutant construction and complementation in this study

\begin{tabular}{|c|c|c|}
\hline Primer & Sequence $^{a}$ & Purpose \\
\hline Ispl-F1 & GGGGTACCACGCCCTCGCACGCCTTCGC $(K p n l)$ & To amplify a 1072-bp upstream homologue arm of Isp 1 \\
\hline $\mid s p 1-\mathrm{R} 1$ & CCCAAGCTTCATCACCGCCGACGCCAAGT (HindIII) & \\
\hline Isp1-F2 & CCCAAGCTTCGGCGAGGGTGAGGGCAAGC (HindIII) & To amplify a 638-bp downstream homologue arm of Isp 1 \\
\hline Isp1-R2 & GCTCTAGACGGCAGCGGATAGCGGAAGT (Xbal) & \\
\hline Isp2-F1 & GGGGTACCTTCTGCCCGTGCTGCCTGTT (Kpnl) & To amplify a 788-bp upstream homologue arm of Isp2 \\
\hline Isp2-R1 & CCCAAGCTTCTGGGGCATCGTCGCTGAAG (HindIII) & \\
\hline Isp2-F2 & CCCAAGCTTTCGTAGGCGGCGGCGGAGGT (HindIII) & To amplify a 875-bp downstream homologue arm of Isp2 \\
\hline Isp2-R2 & GCTCTAGACTGCTGTGGGTCGGCGTGCT $(X b a l)$ & \\
\hline Isp3-F1 & GGGGTACCTCGCTGGAGTGGGGAGGCAT (Kpnl) & To amplify a 553-bp upstream homologue arm of Isp3 \\
\hline Isp3-R1 & CCCAAGCTTGCGTCGGTGTGCTGCTCAAG (HindIII) & \\
\hline Isp3-F2 & CCCAAGCTTCGGCTTCCAGGTAGGTGTAG (HindIII) & To amplify a 379-bp downstream homologue arm of Isp3 \\
\hline Isp3-R2 & GCTCTAGAGCGGCAACTCCAACAAGACC (Xbal) & \\
\hline Ispl-F & GGGGTACCGGTCTCGGCTCGCATCGGTC (Kpnl) & To amplify a 1275-bp fragment containing intact Ispl and its predicted promoter \\
\hline Ispl-R & CCCAAGCTTGCGAGCAGAAGCCCGAGTAC (HindIII) & \\
\hline Isp2-F & CCCAAGCTTCAAGAAGACCGCCAAGACCG (HindIII) & To amplify a 1591-bp fragment containing intact /sp2 and its predicted promoter \\
\hline Isp2-R & GCTCTAGAGACCACCAGGACGGCGAATG (Xbal) & \\
\hline Isp3-F & GCTCTAGAAGAATGTCGGCGTCGTCGTC $($ Xbal) & To amplify a 1247-bp fragment containing intact Isp3 \\
\hline Isp3-R & GGGGTACCTGGGGCGATGGAAGCAAGGG $(K p n l)$ & \\
\hline Gm-F & GTTAGGTGGCGGTACTTGGGTCG & To amplify a 500-bp DNA fragment of the gentamycin-resistance gene \\
\hline Gm-R & ATGTTACGCAGCAGCAACGATGT & \\
\hline
\end{tabular}

a Restriction enzyme digestion site are underlined

\section{Assay of extracellular lytic enzymes}

Production of extracellular chitinase, cellulase and protease by wildtype $\mathrm{OH} 11$ and its derivatives was evaluated following methods used previously in our laboratory (Qian et al. 2013, 2014). Briefly, chitin and cellulose hydrolysis were tested using agar media containing $1 \%$ colloidal chitin and 1\% carboxymethyl cellulose (CMC), respectively (Kobayashi et al. 2005), while proteolytic activity was measured as diffusion-clearing zones on milk agar (Folman et al. 2003). For each experiment involving an enzyme type, there were three replicates assays for each bacterial strains, and the experiment was performed three times.

\section{HSAF analysis}

The wild-type OH11 and its derivatives were evaluated for HSAF production by first cultivating each strain in $1 / 10 \mathrm{TSB}$ at $28{ }^{\circ} \mathrm{C}$ for $13 \mathrm{~h}$ (wildtype) or $17 \mathrm{~h}$ (mutants); this yielded cultures at early stationary phase and similar population levels as determined from the individual growth curves (Additional file 1: Figure S1). HSAF was extracted from these cultures and detected by HPLC (High-Performance Liquid Chromatography) as described previously (Qian et al. 2013, 2014; Yu et al. 2007). HSAF content was expressed as a 'peak area/OD 600 ' index as described previously (Wang et al. 2014), where the 'peak area' is the area under the peak corresponding to HSAF in the HPLC analysis, while the $\mathrm{OD}_{600}$ represents the optical density of the culture at the time point used for HSAF extraction. Each strain was evaluated for HSAF production in three biological experiments, and in each experiment, three replicate cultures of each bacterial strain were assayed.

\section{Extraction and analysis of WAP-8294A2}

The wild-type $\mathrm{OH} 11$ and the $l s p$ mutants were grown in $1 / 10 \mathrm{TSB}$ for 13 and $17 \mathrm{~h}$, respectively, and a $1 \mathrm{~mL}$ aliquot of each culture was transferred to $50 \mathrm{~mL}$ of fresh $1 / 10$ TSB broth, which then was incubate at $28{ }^{\circ} \mathrm{C}$ for 3 days with shaking at $200 \mathrm{rpm}$. The extraction of WAP-8294A2 from broth and HPLC analysis of the antibiotic was performed as described previously (Zhang et al. 2011, 2014). Prior to WAP-8294A2 extraction, $50 \mathrm{~mL}$ of culture was centrifuged, and the supernatant was collected, which was further adjusted to a $\mathrm{pH}$ of 2.5 with $1 \mathrm{~N} \mathrm{HCl}$. Then the acidic supernatant was extracted with n-butanol/ ethyl acetate $(1 / 1$, vol) containing $0.05 \%$ TFA (trifluoroacetic acid). The organic phase was dried, and the residue was dissolved in $2 \mathrm{~mL}$ methanol containing $0.05 \%$ TFA. This final solution, defined as WAP-8294A2 extract, was used for HPLC analysis. 


\section{Statistical analysis}

All analyses were conducted using SPSS 14.0 (SPSS Inc., Chicago, IL, USA). The hypothesis test of percentages ( $t$ test, $P=0.05$ or 0.01 ) was used to identify significant differences in HSAF production between the wild-type $\mathrm{OH} 11$ and particular derivative strains.

\section{Results}

\section{L. enzymogenes produces three $\mathrm{Ax} 2 \mathbf{1}_{\text {xoo-like proteins }}$}

To determine whether L. enzymogenes produces Ax21family proteins, we searched the genome of $L$. enzymogenes strain $\mathrm{OH} 11$ for genes coding for proteins homologous to $\mathrm{Ax} 21_{\mathrm{Xoo}}$. This analysis led to identification of three predicted $\mathrm{Ax} 21_{\mathrm{Xoo}}$-homologous proteins in L. enzymogenes. Due to they being small molecule weight proteins in L. enzymogenes, they were designated as Lsp1 (216 aa), Lsp2 (217 aa) and Lsp3 (216 aa), and they shared $41 \%$ (E value $3 \mathrm{e}-038$ ), $28 \%$ (E value $2 \mathrm{e}-013$ ) and $23 \%$ (E value $3 \mathrm{e}-006)$ identity, respectively, to $\mathrm{Ax} 21_{\mathrm{Xoo}}(194 \mathrm{aa})$ at the amino-acid level. Furthermore, the Lsp proteins were similar, but not identical, to each other as to amino acid sequence, with Lsp1 sharing 33\% (E value $8 \mathrm{e}-025)$ and $35 \%$ ( $\mathrm{E}$ value $3 \mathrm{e}-023$ ) identity to Lsp2 and Lsp3, respectively, and Lsp2 having 43\% identity (E value $1 \mathrm{e}-049$ ) with Lsp3. All three Lsp proteins contained a secretory signal-peptide sequence, similar to that of $\mathrm{Ax} 21_{\mathrm{Sm}}$ and $\mathrm{Ax} 21_{\mathrm{Xoo}}$ (Fig. 1), suggesting that Lsp are secreted proteins. Analysis of the spatial positions of the genes for these proteins revealed them to be separated from each other in the genome of L. enzymogenes OH11 (Additional file 1: Figure S2). Collectively, these results indicated that $L$. enzymogenes produces three unique $\mathrm{Ax} 21_{\mathrm{Xoo}}$-like proteins.
Lsp proteins are not involved in regulating T4P-mediated twitching motility and extracellular lytic enzymes production

To explore the function of the Lsp proteins, we generated seven in-frame deletion mutants in strain OH11 (Additional file 1: Tables S1, S2), including three having a single mutation ( $\Delta l s p 1, \Delta l s p 2$ and $\Delta l s p 3)$, three containing double mutations $(\Delta l s p 12, \Delta l s p 13$ and $\Delta l s p 23)$, and one triple mutation $(\Delta l s p 123)$. The mutants were evaluated in comparison to the wild-type $\mathrm{OH} 11$ for twitching motility and production of extracellular lytic enzymes. When cultured under conditions favorable to expression of twitching motility, we found that all $l s p$ mutants, similar to the wild-type $\mathrm{OH} 11$, produced mobile cells or cell clusters at the margin of the respective colonies (Fig. 2a), which is indicative of twitching motility in L. enzymogenes. This result suggests that the Lsp proteins are not involve in the regulation of T4P-mediated twitching motility in $L$. enzymogenes. When cultured on indicator media for protease, cellulase and chitinase production, all $l s p$ mutants displayed wild-type levels in producing these three extracellular lytic enzymes (Fig. 2b), suggesting that Lsp proteins are also not involved in regulating the production of extracellular lytic enzymes by L. enzymogenes.

\section{Lsp proteins play a key role in regulating HSAF biosynthesis}

Comparison of wildtype $\mathrm{OH} 11$ and its derivative strains revealed the Lsp proteins have a regulatory role in HSAF biosynthesis in L. enzymogenes focused on HPLC analysis of the antibiotic extracted from broth cultures showed that a deletion of any one of the $l s p$-genes caused a significant decrease in HSAF production in the mutant

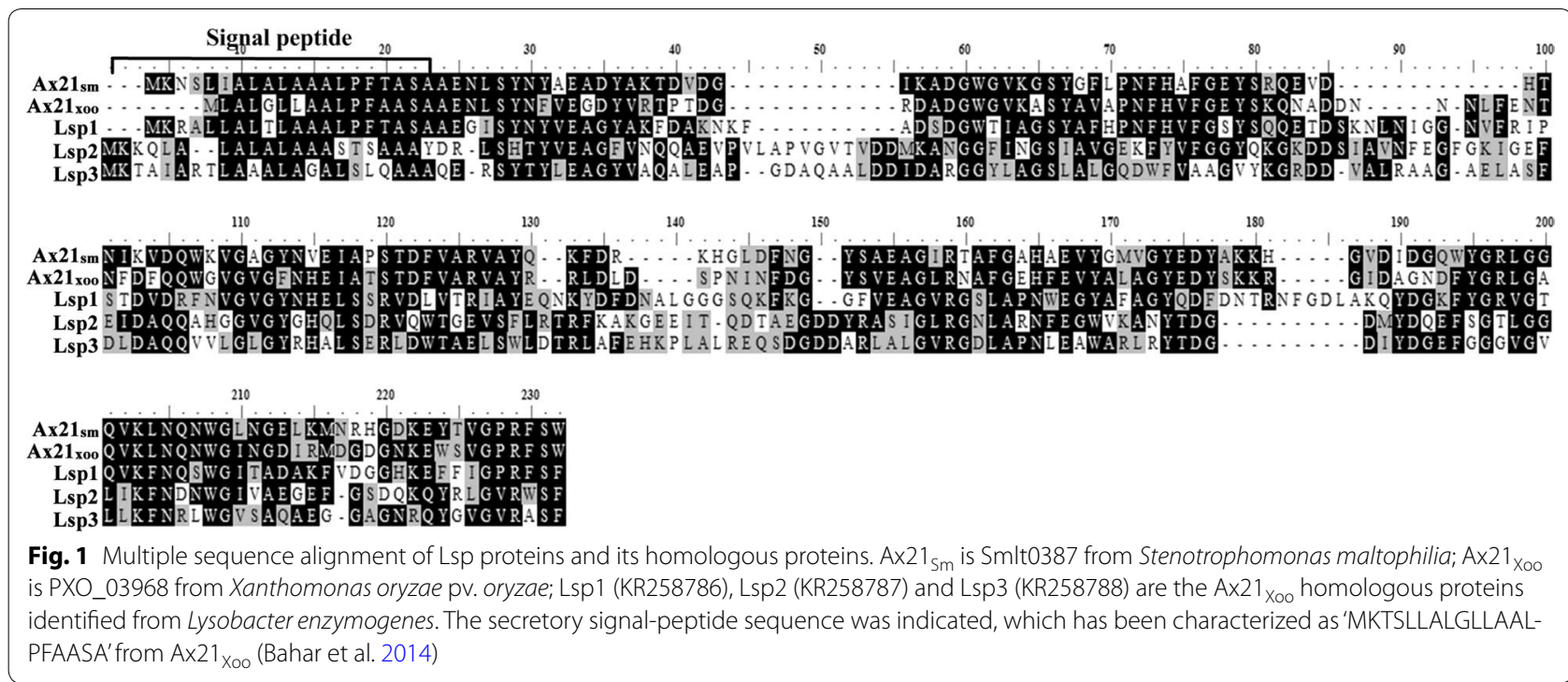



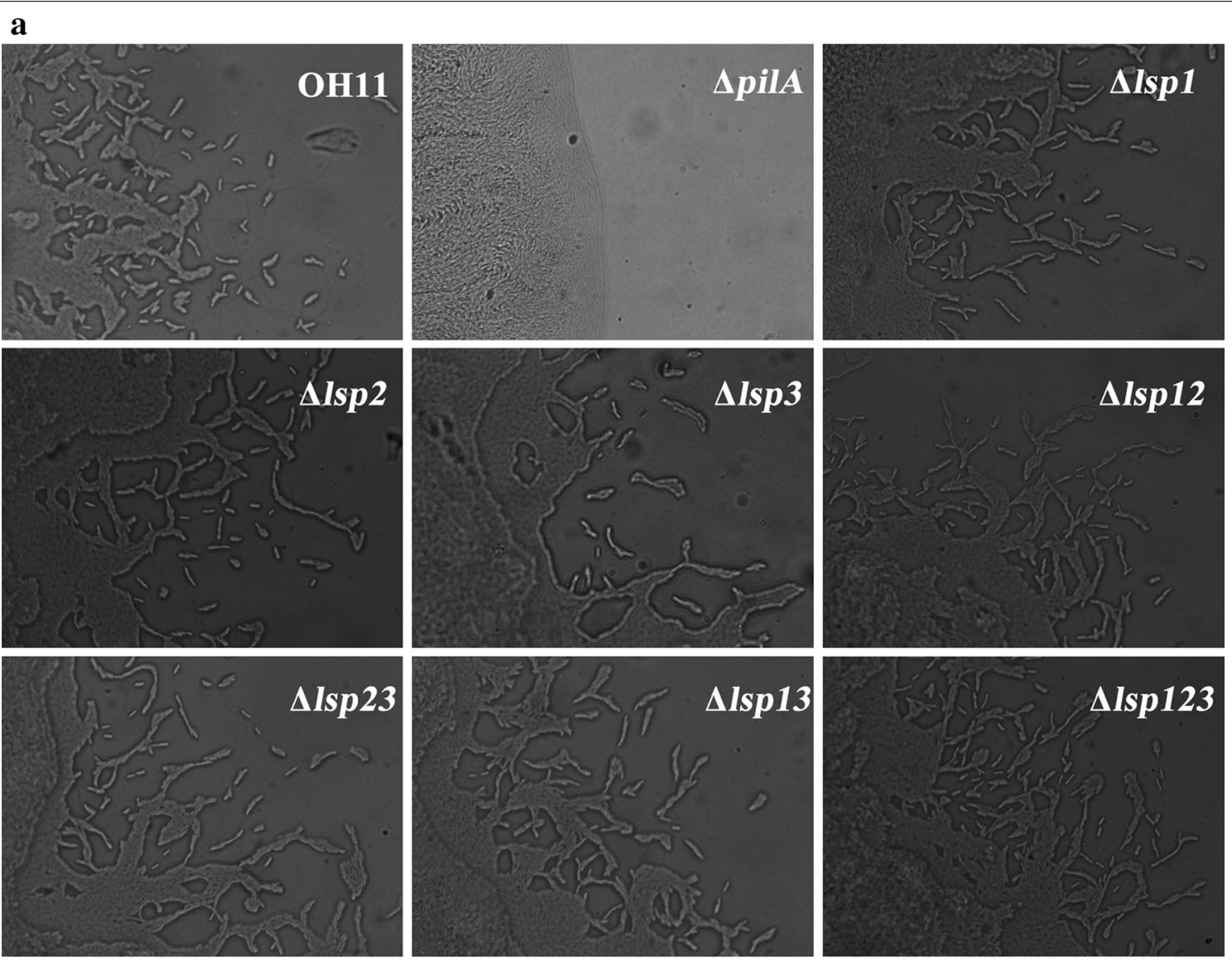

b

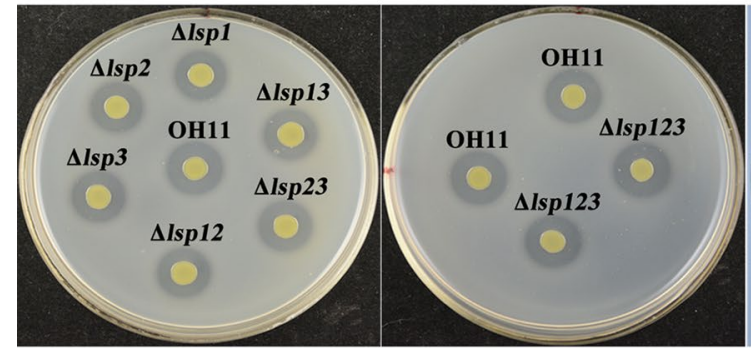

Protease

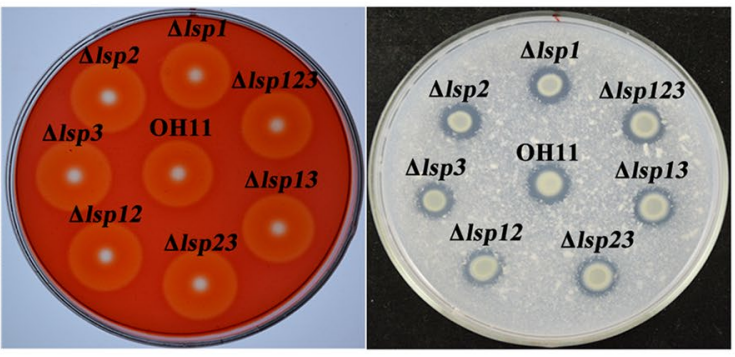

Cellulase

Chitinase

Fig. 2 Deletion of Lsp protein genes individually or in various combinations in Lysobacter enzymogenes did not disrupt twitching motility (a) and production of extracellular protease, cellulase and chitinase (b). In $\mathbf{a}$, individual cells or cell clusters produced at the margin of colony are characteristic of twitching motility in L. enzymogenes. OH11: wild-type strain of L. enzymogenes; $\Delta$ pilA: twitching-motility deficient mutant used as a negative control; $\Delta / s p 1, \Delta / s p 2$ and $\Delta / s p 3$ : mutants with in-frame deletions 1 sp 1, Isp2 and Isp3, respectively; $\Delta / s p 12, \Delta / s p 13$ and $\Delta / s p 23$ : double in-frame deletion mutants with double deletions at Isp1 and Isp2, Isp 1 and Isp3, and Isp2 and Isp3, respectively; $\Delta / s p 123$ : the triple deletion mutant lacking Isp 1, Isp2 and $/ s p 3$

strain compared to the wild-type OH11 (Fig. 3). Furthermore, in trans complementation of each mutation by introduction of a plasmid containing the intact deleted gene rescued the deficiency of each mutation, whereas introduction of the empty vector into each mutant had no significant effect (Fig. 3). HSAF biosynthesis in each of the three double deletion mutants $(\Delta l s p 12, \Delta l s p 13$ and $\Delta l s p 23)$ and the triple deletion mutant $(\Delta l s p 123)$ also was depressed compared to that of the wild-type, but not entirely eliminated; the decrease in HSAF yield in each double or triple deletion mutant occurred to the similar degree as every single deletion mutant (Fig. 3). These results indicate that each Lsp protein is involved in regulating HSAF biosynthesis in L. enzymogenes, but the 


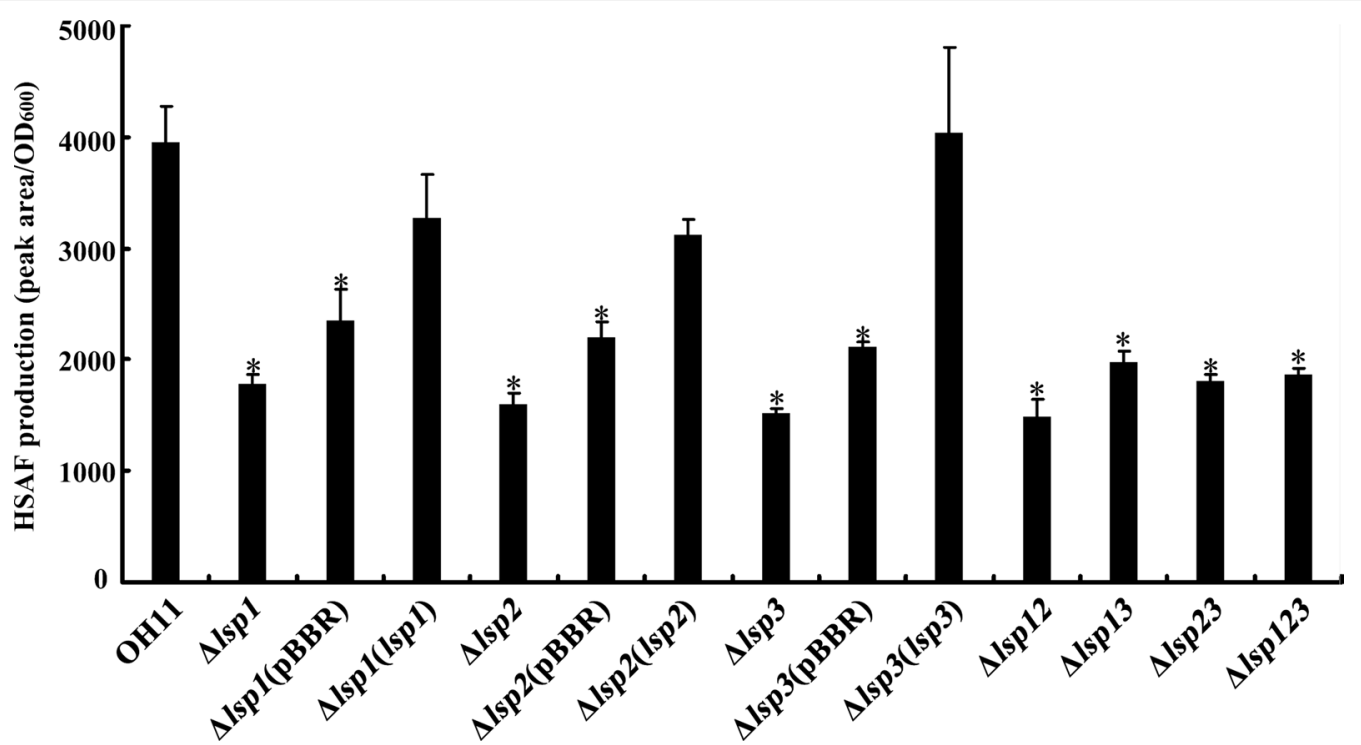

Fig. 3 Deletion of Isp genes individually or in various combinations in Lysobacter enzymogenes significantly impaired HSAF production. The identities of strains $\mathrm{OH} 11, \Delta / s p 1, \Delta / s p 2 \Delta / s p 3, \Delta / s p 12, \Delta / s p 13, \Delta / s p 23$ and $\Delta / s p 123$ are provided in the Fig. 2 caption. $\Delta / s p 1(\mathrm{pBBR}), \Delta / s p 2(\mathrm{pBBR})$, and $\Delta / s p 3(\mathrm{pBBR})$ are the respective mutant strain containing the empty vector, pBBR1-MCS5. $\Delta / s p 1(\mid s p 1), \Delta / s p 2(\mid s p 2), \Delta / s p 3(\mid s p 3)$ are the complemented strain of each mutant in which the deleted lsp gene(s) was expressed in the plasmid. The values shown in this figure represent the means of three experiments. Vertical bars represent standard errors. The asterisk above a bar indicates a significant difference $(p<0.05)$ between the respective strain and the wild-type strain $\mathrm{OH} 11$

proteins in dual combinations or all together do not exert additive effects.

\section{Lsp proteins are involved in the regulation of WAP-8294A2} biosynthesis

We used the battery of $l s p$ mutants to explore the role of Lsp proteins in the regulation of WAP-8294A2 biosynthesis. As shown in Fig. 4, individual deletion of $l s p 1$, $l s p 2$ or $l s p 3$ led to a visible reduction in WAP-8294A2 yield, suggesting that each Lsp protein played a key role in regulating WAP-8294A2 biosynthesis. Furthermore, the three double mutants $(\Delta l s p 12, \Delta l s p 13$ and $\Delta l s p 23)$, and the triple mutant $(\Delta l s p 123)$ produced WAP-8294A2 at levels similar to that produced by each single mutant, implying that the Lsp proteins do not exert additive effects in regulating WAP-8294A2 biosynthesis.

\section{Discussion}

The involvement of Ax21 family proteins in regulating virulence-related traits was previously documented in certain pathogenic species of Xanthomonas and Stenotrophomonas, establishing the initial understanding of the regulatory function of this family of proteins in bacteria (Qian et al. 2013; McCarthy et al. 2011). However, the role of Ax21 family proteins in non-pathogenic bacteria had not been established until this study. Here, we show that Ax21-family proteins (Lsp) in the biological control agent L. enzymogenes play a vital role in regulating the biosynthesis of antimicrobial secondary metabolites. This function has not been reported in any other bacterial species in which Ax21 family proteins are known to be produced.

The Lsp proteins regulate the production of HSAF and WAP-8294A2 in L. enzymogenes. The ability to produce antibiotics to inhibit competitors or to inactivate organisms that serve as potential nutrient sources is a critical factor for the existence of a soil-inhabiting, non-pathogenic organism, just as virulence against a host is essential for the existence of a pathogenic organism factor. The fact the Ax21 family protein are associated with competitive ability in a non-pathogen and with virulence in pathogenic bacterial species suggest that these proteins evolved to regulate key survival/ecological traits. The Lsp proteins do regulate the trait (HSAF and WAP-8294A2) critical to the ecological functioning of L. enzymogenes, but the deletion of $l s p$ genes together and in combination had no detectable effects on the ability of the bacterium to produce lytic enzymes or to engage in twitching motility. The latter finding was particularly surprising considering that Ax21 family proteins have been shown to regulate flagella-driven swimming motility in Xoo and $S$. maltophilia (McCarthy et al. 2011; Ferrer-Navarro et al. 2013; Park et al. 2014). Our findings do suggest that the regulatory role of Ax21 family proteins in cell motility is variable among different members of the Xanthomonadaceae family. 


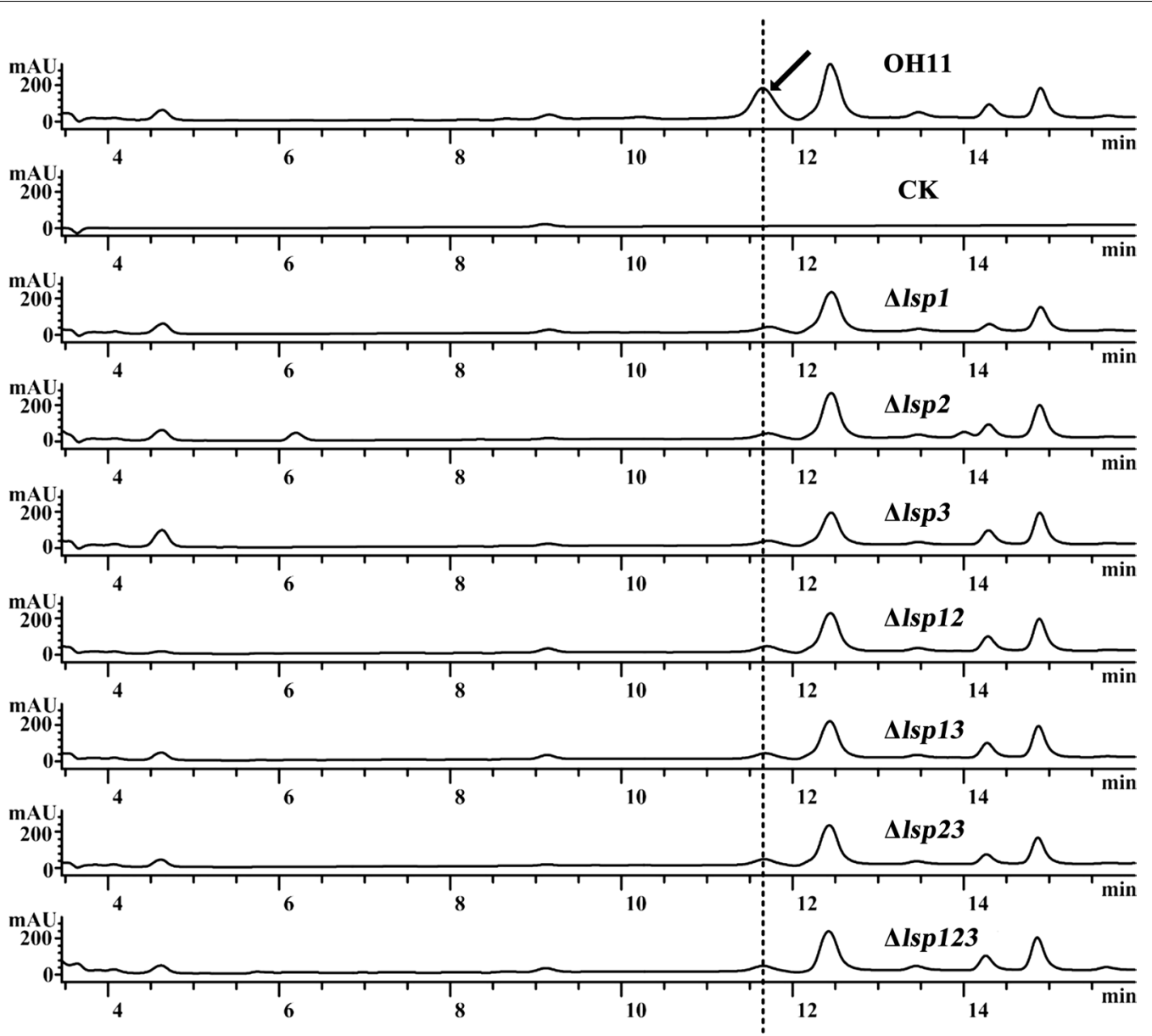

Fig. 4 Inactivation of Isp genes individually or in various combinations caused a decrease in the WAP-8294A2 production. The identity of each strain in this figure is provided in the captions for Figs. 2 and 3. 'CK' is the solvent (methanol)-only control. The arrow indicates the peak corresponding to WAP-8294A2

In the present study, we found that the regulation of antibiotic production in L. enzymogenes involved three unique Lsp proteins whose genes occur in separate locations in $L$. enzymogenes genome. In contrast, only one Ax21-family protein has been reported in Xoo (Bahar et al. 2014), while two Ax21-like proteins (Smlt0387 and Smlt0184) were identified in S. maltophilia (Devos et al. 2015). Among the two Ax21-family proteins found in S. maltophilia, only one (Smlt0387) has been shown to function in the regulation of motility, biofilm formation and virulence (FerrerNavarro et al. 2013; McCarthy et al. 2011), while the role of Smlt0184 remains unknown. These studies collectively show that different members of the Xanthomonadaceae family have the potential to express different numbers of Ax21 family proteins. The biological significance for $L$. enzymogenes needing to produce three different Lsp proteins is an open question. It is also puzzling that the Lsp proteins did not exhibit an additive effect in regulating antibiotic production given that Ax21-family proteins are presumed to act as quorum molecules; indeed, relative virulence among strains of $S$. maltophilia was correlated with the amounts of Ax21 protein produced (Ferrer-Navarro et al. 2013). If the Lsp proteins are quorum sensing molecules, then a possible explanation for the non-additive phenomenon is that the three Lsp proteins are active in a trimer-like complex that requires all three proteins. It might also be possible that Lsp proteins function in a mechanism distinct from quorum sensing and that each protein acts on different successive steps in a single pathway, such that when any one step is blocked, then the entire pathway is blocked accordingly.

\section{Additional file}

Additional file 1: Table S1. Confirmation of single mutation by PCR in this study. Table S2. Validation of double or triple mutation by PCR in this study. Figure S1. Lsp proteins contributed to the growth pattern of Lysobacter enzymogenes. Figure S2. Genomic organization of three Lspcoding genes in Lysobacter enzymogenes. 


\begin{abstract}
Abbreviations
HSAF: heat stable antifungal factor; Lsp: small molecule protein in Lysobacter enzymogenes; Xoo: Xanthomonas oryzae pv. oryzae; Omp1X: outer membrane protein 1 in Xoo; Xoc: Xanthomonas oryzae pv. oryzicola; MRSA: methicillinresistant Staphylococcus aureus; T4P: type IV pili; Km: kanamycin; Gm: gentamicin; PCR: polymerase chain reaction; CMC: carboxymethyl cellulose; HPLC: high-performance liquid chromatography; TFA: trifluoroacetic acid.
\end{abstract}

\section{Authors' contributions}

RPW carried out the molecular genetic studies, participated in the sequence alignment and drafted the manuscript. HYX carried out the molecular genetic studies, participated in the sequence alignment and the design of the study. YYZ and JZ performed the statistical analysis. GY, GLQ and FQL conceived the study, and participated in its design and coordination and helped to draft the manuscript. All authors read and approved the final manuscript.

\section{Author details}

${ }^{1}$ Institute of Plant Protection, Jiangsu Academy of Agricultural Sciences, Nanjing 210014, China. ${ }^{2}$ College of Plant Protection, Key Laboratory of Integrated Management of Crop Diseases and Pests, Ministry of Education, Nanjing Agricultural University, Nanjing 210095, China. ${ }^{3}$ Department of Plant Pathology, University of Nebraska-Lincoln, Lincoln, NE 68583-0722, USA.

\section{Acknowledgements}

We thank Prof. Pamela Ronald (UC Davis) for reviewing an early version of this manuscript.

\section{Competing interests}

The authors declare that they have no competing interests.

\section{Availability of data and materials}

All the data are presented in the main paper or Additional file 1.

\section{Funding}

This study was funded by National Natural Science Foundation of China (31371981 to G. Qian), the grants from Jiangsu Academy of Agricultural Sciences and Jiangsu Province [ZX(15)1006; CX(16)1049; BE2014386; BE2015354 to F. Liu], Special Fund for Agro-Scientific Research in the Public Interest (201303015 to G. Qian and F. Liu), and National pear industry technology system (CARS-29-09 to G. Qian and F. Liu). Gary Yuen's efforts were funded by a grant from the Agricultural Research Division of the Institute of Agriculture and Natural Resources, University of Nebraska-Lincoln to support his participation in the multistate research project W3147: Managing Plant Microbe Interactions in Soil to Promote Sustainable Agriculture. The funders did not have a role in the design of the study and collection, analysis, or interpretation of data or in writing the manuscript.

\section{Publisher's Note}

Springer Nature remains neutral with regard to jurisdictional claims in published maps and institutional affiliations.

Received: 31 March 2017 Accepted: 1 June 2017

Published online: 13 June 2017

\section{References}

Bahar O, Pruitt R, Luu DD, Schwessinger B, Daudi A, Liu FR, Ruan R, FontaineBodin L, Koebnik R, Ronald P (2014) The Xanthomonas Ax21 protein is processed by the general secretory system and is secreted in association with outer membrane vesicles. Peer J 2:e242

Christensen P, Cook FD (1978) Lysobacter, a new genus of nonhiting, gliding bacteria with a high base ratio. Int I Syst Bacteriol 28(3):367-393

Devos S, Van Oudenhove L, Stremersch S, Van Putte W, De Rycke R, Van Driessche G, Vitse J, Raemdonck K, Devreese B (2015) The effect of imipenem and diffusible signaling factors on the secretion of outer membrane vesicles and associated A×21 proteins in Stenotrophomonas maltophilia. Front Microbiol 6:298

Ferrer-Navarro M, Planell R, Yero D, Mongiardini E, Torrent G, Huedo P, Martinez P, Roher N, Mackenzie S, Gibert I, Daura X (2013) Abundance of the quorum-sensing factor Ax21 in four strains of Stenotrophomonas maltophilia correlates with mortality rate in a new zebrafish model of infection. PLoS ONE 8:e67207

Folman LB, Postma J, van Veen JA (2003) Characterization of Lysobacter enzymogenes (Christensen and Cook 1978) strain 3.1T8, a powerful antagonist of fungal diseases of cucumber. Microbiol Res 158:107-115

Han Y, Wang Y, Tombosa S, Wright S, Huffman J, Yuen GY, Qian GL, Liu FQ Shen YM, Du LC (2015) Identification of a small molecule signaling factor that regulates the biosynthesis of the antifungal polycyclic tetramate macrolactam HSAF in Lysobacter enzymogenes. Appl Microbiol Biotechnol 99(2):801-811

Hayward AC, Fegan N, Fegan M, Stirling GR (2010) Stenotrophomonas and Lysobacter: ubiquitous plant-associated gramma-proteobacteria of developing significance in applied microbiology. J Appl Microbiol 108(3):756-770

Hoang TT, Karkhoff-Schweizer RR, Kutchma AJ, Schweizer HP (1998) A broadhost-range Flp-FRT recombination system for site-specific excision of chromosomally-located DNA sequences: application for isolation of unmarked Pseudomonas aeruginosa mutants. Gene 212(1):77-78

Kato A, Nakaya S, Ohashi Y, Hirata H (1997) WAP-8294A2, a novel anti-MRSA antibiotic produced by Lysobacter sp. J Am Chem Soc 119:6680-6681

Kobayashi DY, Yuen GY (2007) The potential of Lysobacter spp. as bacterial biological control agents for plant diseases. CAB Rev Perspect Agric Vet Sci Nutr Nat Res 2(7):1. doi:10.1079/PAVSNNR20072007

Kobayashi DY, Reedy RM, Palumbo JD, Zhou JM, Yuen GY (2005) A clp gene homologue belonging to the Crp gene family globally regulates lytic enzyme production, antimicrobial activity, and biological control activity expressed by Lysobacter enzymogenes strain C3. Appl Environ Microbiol 71(1):261-269

Kovach ME, Elzer PH, Hill DS, Robertson GT, Farris MA, Roop RM, Peterson KM (1995) Four new derivatives of the broad-host-range cloning vector pBBR1MCS, carrying different antibiotic-resistance cassettes. Gene 166(1):175-176

Lee SW, Han SW, Sririyanum M, Park CJ, Seo YS, Ronald PC (2009) A type I-secreted, sulfated peptide triggers XA21-mediated innate immunity. Science 326(5954):850-853

Li S, Du L, Yuen G, Harris SD (2006) Distinct ceramide synthases regulate polarized growth in the filamentous fungus Aspergillus nidulans. Mol Biol Cell 17(3):1218-1227

Li S, Jochum CC, Yu F, Zaleta-Rivera K, Du L, Harris SD, Yuen GY (2008) An antibiotic complex from Lysobacter enzymogenes strain C3: antimicrobial activity and role in plant disease control. Phytopathology 98(6):695-701

Li YY, Chen HT, Ding YJ, Xie YX, Wang HX, Cerny RL, Shen YM, Du LC (2014) Iterative assembly of two separate polyketide chains by the same singlemodule bacterial polyketide synthase in the biosynthesis of HSAF. Angew Chem Int Ed Engl 53(29):7524-7530

Lou LL, Qian GL, Xie YX, Hang JL, Chen HT, Zaleta-Rivera K, Li YY, Shen YM, Dussault PH, Liu FQ, Du LC (2011) Biosynthesis of HSAF, a tetramic acidcontaining macrolactam from Lysobacter enzymogenes. J Am Chem Soc 133:643-645

McCarthy Y, Dow JM, Ryan RP (2011) The Ax21 protein is a cell-cell signal that regulates virulence in the nosocomial pathogen Stenotrophomonas maltophilia. J Bacteriol 193(22):6375-6378

Palumbo JD, Sullivan RF, Kobayashi DY (2003) Molecular characterization and expression in Escherichia coli of three $\beta$-1, 3-glucanae genes from Lysobacter enzymogenes strain N4-7. J Bacteriol 185(15):4362-4370

Park HJ, Lee SW, Han SW (2014) Proteomic and functional analyses of a novel porin-like protein in Xanthomonas oryzae pv. oryzae. J Microbiol 52(12):1030-1035

Patel N, Cornejo M, Lambert D, Craig A, Hillman Bl, Kobayashi DY (2011) A multifunctional role for the type IV pilus in the bacterial biological control agent Lysobacter enzymogenes. Phytopathology 101:S138

Patel N, Oudemans PV, Hillman BI, Kobayashi DY (2013) Use of the tetrazolium salt MTT to measure cell viability effects of the bacterial antagonist Lysobacter enzymogenes on the filamentous fungus Cryphonectria parasitica. Antonie Van Leeuwenhoek 103(6): 1-10

Pruitt RN, Schwessinger B, Joe A, Thomas N, Liu F, Albert M, Robinson MR, Chan LJG, Luu DD, Chen H, Bahar O, Daudi A, Vleesschauwer DD, Caddell D, Zhang WG, Zhao XX, Li X, Heazlewood JL, Ruan DL, Majumder D, Chern MS, Kalbacher H, Midha S, Patil PB, Sonti RV, Petzold CJ, Liu CC, Brodbelt JS, Felix G, Ronald PC (2015) The rice immune receptor XA21 recognizes 
a tyrosine-sulfated protein from a Gram-negative bacterium. Sci Adv 1:e1500245

Qian GL, Hu BS, Jiang YH, Liu FQ (2009) Identification and characterization of Lysobacter enzymogenes as a biological control agent against some fungal pathogens. Agr Sci China 8(1):68-75

Qian GL, Wang YS, Qian DY, Fan JQ, Hu BS, Liu FQ (2012) Selection of available suicide vectors for gene mutagenesis using chiA (a chitinase encoding gene) as a new reporter and primary functional analysis of chiA in Lysobacter enzymogenes strain OH11. World J Microb Biot 28(2):549-557

Qian GL, Wang YL, Liu YR, Xu FF, He YW, Du LC, Venturi V, Fan JQ, Hu BS, Liu FQ (2013) Lysobacter enzymogenes uses two distinct cell-cell signaling systems for differential regulation of secondary-metabolite biosynthesis and colony morphology. Appl Environ Microbiol 79(21):6604-6616

Qian GL, Xu FF, Venturi V, Du LC, Liu FQ (2014) Roles of a solo LuxR in the biological control agent Lysobacter enzymogenes strain $\mathrm{OH} 11$. Phytopathology 104(3):224-231

Reichenbach H (2006) The genus Lysobacter. Prokaryotes 6:939-957

Wang YS, Zhao YX, Zhang J, Zhao YY, Shen Y, Su ZH, Xu GG, Du LC, Huffman JM, Venturi V, Qian GL, Liu FQ (2014) Transcriptomic analysis reveals new regulatory roles of $\mathrm{Clp}$ signaling in secondary metabolite biosynthesis and surface motility in Lysobacter enzymogenes $\mathrm{OH} 11$. Appl Microbiol Biotechnol 98(21):9009-9020
Xie YX, Wright S, Shen YM, Du LC (2012) Bioactive natural products from Lysobacter. Nat Prod Rep 29(11):1277-1287

Yu F, Zaleta-Rivera K, Zhu X, Huffman J, Millet JC, Harris SD, Yuen G, Li XC, Du L (2007) Structure and biosynthesis of heat-stable antifungal factor (HSAF), a broad-spectrum antimycotic with a novel mode of action. Antimicrob Agents Chemother 51(1):64-72

Zhang Z, Yuen GY (2000) The role of chitinase production by Stenotrophomonas maltophilia strain C3 in biological control of Bipolaris sorokiniana. Phytopathology 90(4):384-389

Zhang W, Li YY, Qian GL, Wang Y, Chen HT, Li YZ, Liu FQ, Shen YM, Du LC (2011) Identification and characterization of the anti-methicillin-resistant Staphylococcus aureus WAP-8294A2 biosynthetic gene cluster from Lysobacter enzymogenes $\mathrm{OH} 1$ 1. Antimicrob Agents Chemother 55(12):5581-5589

Zhang J, Du LC, Liu FQ, Xu FF, Hu BS, Venturi V, Qian GL (2014) Involvement of both PKS and NRPS in antibacterial activity in Lysobacter enzymogenes OH11. FEMS Microbiol Lett 355(2):170-176

Zhou X, Qian GL, Chen Y, Du LC, Liu FQ, Yuen GY (2015) PilG is involved in the regulation of twitching motility and antifungal antibiotic biosynthesis in the biological control agent Lysobacter enzymogenes. Phytopathology 105(10):1318-1324

\section{Submit your manuscript to a SpringerOpen ${ }^{\circ}$ journal and benefit from:}

- Convenient online submission

- Rigorous peer review

- Open access: articles freely available online

- High visibility within the field

- Retaining the copyright to your article

Submit your next manuscript at $\boldsymbol{\nabla}$ springeropen.com 